\title{
LA VÍCTIMA COMO PILAR DE LA JUSTICIA RESTAURATIVA MEXICANA
}

\author{
A VÍTIMA COMO PILAR DA JUSTIÇA RESTAURATIVA MEXICANA
}

THE VICTIM AS A PILAR OF MEXICAN RESTORATIVE JUSTICE

José Zaragoza Huerta ${ }^{1}$

\section{Resumen}

El presente trabajo aborda la una realidad que representa la inclusión de la justicia restaurativa a las víctimas de un delito. Se analiza la reforma constitucional del año 2008, que introduce la justicia restaurativa que no se prevé de nomen iuris sí en el cuerpo normativo reformado se ve impregnado de esta idea de justicia. Lo que represente nuevos paradigmas de actuación de todos los partícipes del drama penal, particularmente la víctima, aquella que había sido relegada en el saliente modelo punitivo del país.

Palabras clave: Reforma constitucional, justicia restaurativa, víctima, delincuente.

\section{Resumo}

Este artigo aborda a realidade que representa a inclusão da justiça reparadora para as vítimas de crime. Se analisa a reforma constitucional de 2008 , que introduz a justiça restaurativa que não se prevê como nomen iuris, mas sim, no corpo normativo reformado, que se vê impregnado desta ideia de justiça. O que representa novos paradigmas de atuação de todos os partícipes do drama penal, particularmente a vítima, essa que tinha relegada no saliente modelo punitivo do país.

Palabras-clave: Reforma constitucional, a justiça restaurativa, vítima, agressor.

\section{Abstract}

In this paper the author exposes the reality that represents the inclusion of restorative justice for victims of crime. In the paper analyses the constitutional reform of 2008, introducing restorative Justice, that is not expected in nomen iuris but, in the reformed regulatory body is impregnated with this idea of justice. Which represent new paradigms of action of all participants in the criminal drama, particularly the victim, one that had been relegated in the punitive model country.

Keywords: Constitutional reform, restorative justice, victim, offender.

\footnotetext{
${ }^{1}$ Doctor en derecho (Universidad de Alcalá de Henares). Docente e investigador del CITEJyC, Facultad de Derecho y Criminología, UANL. México. Email: jose.zaragozahr@uanl.edu.mx).
} 


\section{INTRODUCCIÓN}

La reforma constitucional del año 2008, denominada: “Del Sistema Mexicano de Seguridad y Justicia", respondió necesariamente a la democratización institucional del Estado mexicano (atendiendo a los compromisos internacionales firmados y ratificados, que pugnan por una reforma globalizadora del procedimiento penal en América Latina² así como la demanda del justicia de la sociedad mexicana.

Dos son los principios o virtudes ${ }^{3}$ que se potencian con la reforma: la seguridad y la justicia. Elementos con los cuales el Estado mexicano procura proporcionar a cada uno lo suyo. No obstante, no podemos olvidarnos de otros principios que vienen a completar dicha pretensión Estatal y que repercuten al interior y exterior del Estado mexicano: el bienestar común, la solidaridad y la seguridad; lo que permitirá que el individuo se configure realmente como destino racional ${ }^{4}$ de las instituciones jurídico-políticas.

Con la reforma constitucional mexicana, pareciera que, en primera instancia, el Estado mexicano se aleja de aquella justicia retributiva ${ }^{5}$ y pretende impulsar una justicia restaurativa plena para las partes intervinientes en el conflicto ${ }^{6}$-distinta, alternativa-, cuya esencia la encontramos en el derecho anglosajón con la denominada alternative dispute resolution; misma que demanda eliminar los abusos y estar impregnada de racionalidad y humanismo para las partes intervinientes ${ }^{7}$, particularmente, se escucha a la víctima del presunto hecho delictivo ${ }^{8}$.

\section{EL IMPACTO DE LA REFORMA CONSTITUCIONAL}

La reforma se viene fraguando a partir del año 2006, pero inicia su andadura en el año 2008; no obstante, se propuso una vacatio legis de ocho años en materia penal y tres en el ámbito penitenciario para que haya una unificación toda la República mexicana.

Esto significa que, por razón del Federalismo, los Congresos de las Entidades Federativas deberían legislar a su interior para adecuar sus correspondientes normativas.

\footnotetext{
2 Rosas Yataco, 2005, p. 5.

${ }^{3}$ Rawls, 1979, p. 19.

${ }^{4}$ Habermas, 2001, p. 124.

${ }^{5}$ Neuman, 2005, p. 8.

6 Pásara, 2004, p.12.

${ }^{7}$ García Valdés, 1997, p. 399.

${ }^{8}$ Villarreal Sotelo, 2011, p. 105.
} 
Toda esta actividad legislativa nos lleva a cuestionarnos: ¿Realmente representó un nuevo paradigma la reforma para la seguridad y justicia mexicana? Consideramos que sí.

El gran aporte de la reforma es la potenciación de derechos, principios y fines que, si bien se contemplaban con anterioridad (pero no se cumplían), ahora al ser elevados a rango constitucional, deben ser garantizados para las partes intervinientes del conflicto; en síntesis: "Dar vigencia plena a las garantías individuales y derechos humanos que consagra la Constitución y brindar la seguridad debida a personas y propiedades ${ }^{9 \prime}$.

Entendemos asimismo, que otro aspecto trascendente de la reforma radica en la búsqueda de salidas alternativas, distantes al Derecho penal. Con ello, se evita acudir inmediatamente al mismo (prima ratio), para recurrir (exclusivamente con observación de los principios que lo legitiman), en casos en los no se haya llegado a un acuerdo entre las partes o bien por circunstancias de gravedad o interés alarma socia ${ }^{10}$ al juicio oral penal. Definitivamente, asistimos a la quita de la venda que obstaculizaba a la justicia ${ }^{11}$.

\section{LA JUSTICIA RESTAURATIVA: EL NUEVO PARADIGMA DE JUSTICIA MEXICANA}

La reforma constitucional introdujo un nuevo paradigma de justicia en México. La justicia restaurativa, la cual responde a "diferentes movimientos preocupados por la humanización del sistema penal y por aliviar el sufrimiento que introduce el delito y sus consecuencias"12.

Podemos señalar que en el ámbito doctrinario latinoamericano existen insuficientes trabajos que han abordado esta temática, así algunos autores la han denominado: justicia conciliadora ${ }^{13}$, reparativa, reparadora, restitutiva, reintegradora, etc. ${ }^{14}$. Quizá la razón de este exiguo interés por estudiarla se deba a que ésta sea un tema relativamente novedoso, visto incluso con cierto escepticismo, por todo lo que implica (cambio cultural) particularmente en el caso mexicano.

Aludir a la justicia restaurativa, significa transformar el conflicto en acuerdo de voluntades tendentes a lograr la paz. Esto es, hacer un viraje hacia una cultura donde la empatía entre las

\footnotetext{
${ }^{9}$ Cámara de Diputados, 2008, p. 2.

10 Muñoz Conde, 1996, p. 21.

${ }^{11}$ García Ramírez, 1970, p. 19.

12 Ríos Martín, et al., 2008, p. 32.

13 Highton, 1998, pp. 71-91.

${ }^{14}$ Kemelmajer De Carlucci, 2004, p. 8.
} 
partes de una contienda es un eslabón determinante para pretender, una vez satisfechas ciertas condiciones, restablecer las cosas al estado inicial, en la medida de lo posible.

Actualmente, no encontramos un concepto unívoco del nuevo paradigma de justicia restaurativa; ello significa que el primer escollo a superar en esta asignatura es poder determinar siquiera su concepto. Si bien podemos establecer una serie de aproximaciones, pareciera que la más apropiada es aquella establecida por las Naciones Unidas que al respecto establece: "se entiende todo proceso en que la víctima, el delincuente $y$, cuando proceda, cualesquiera otras personas o miembros de la comunidad afectados por un delito, participen conjuntamente de forma activa en la resolución de cuestiones derivadas del delito, por lo general con la ayuda de un facilitador".

Lo que se pretende con este nuevo modelo de justicia es que "las partes retomen o reasuman el conflicto personalmente, de pleno acuerdo y ya sin agresión. El sentido es llegar a recomponer las relaciones sociales o hacer entablar nuevas reacciones entre las partes del conflicto, no se resulta sencillo pero tampoco imposible"15.

Debemos de tener presente que si existe complicación por determinar conceptualmente la justicia restaurativa, seguramente el proceso restaurador conlleva más complejidad. En el caso mexicano, se carece de algún modelo establecido como los existentes en otras latitudes ${ }^{16}$; $\sin$ embargo, el hecho de iniciar su camino este nuevo paradigma de justicia restaurativa es un punto de oportunidad que debe aprovecharse en aras de instrumentar modelos propios aprovechando la experiencia de otros arquetipos de derecho comparado ${ }^{17}$.

La implementación de la justicia restaurativa se viene realizando lentamente, prueba de esto es que se ha expedido la Ley Nacional de Mecanismos Alternos de Solución de Controversias en Materia Penal donde se alude a la justicia restaurativa como un método alternativo; lo que significa que hay un rol trascendental de las partes, especialmente de la víctima para llevarla a cabo.

Con este modelo de justicia el proceso de restauración pretende habilitar a las víctimas, al infractor y a los miembros afectados de la comunidad para que participen directa y activamente en la respuesta del delito, con la vista puesta en la reparación y la paz social, alejándose de la visión retributiva del derecho penal buscando superar la lógica del "castigo"18.

\footnotetext{
15 Neuman, 2005, p. 45.

16 Pastrana Aguirre, 2010, p. 61.

17 Torres Estrada, 2002, p. 17.

${ }^{18}$ Cristie, 1981, p. 61.
} 


\section{ASPECTOS POSITIVOS DE LA INTRODUCCIÓN DE LA JUSTICIA RESTAURATIVA EN EL ORDENAMIENTO JURÍDICO MEXICANO}

A partir de los ordenamientos que hemos mencionado supra, sin duda, son más los aspectos positivos que representa la introducción de la justicia restaurativa, mismos que listamos a continuación:

1. Se pone especial atención a las víctimas u ofendidos del delito;

2. La reparación del daño causado tiene un papel trascendente para las partes del conflicto;

3. Se privilegia la cultura del diálogo y el avenimiento por encima de la confrontación;

4. Se pondera cualquier alternativa previa al Derecho penal cumpliéndose a cabalidad el principio de ultima ratio del mismo;

5. Se permuta la finalidad resocializadora de la pena por la restaurativa.

\section{EL ROL DE LA VÍCTIMA EN LA JUSTICIA RESTAURATIVA MEXICANA}

Teniendo como punto de partida a la víctima, aquella que ha sido lesionada de manera objetiva en alguno de sus bienes y que experimenta en forma subjetiva el daño o el malestar o el dolor ${ }^{19}$, el nuevo marco jurídico de protección a ésta lo encontramos en el precepto 20 de la Carta Magna mexicana que destaca entre otros derechos consagrados los siguientes:

1. Ser informado de sus derechos;

2. Facilitarle el acceso a la justicia;

3. Recibir atención médica, psicológica y jurídica;

4. Comunicarse con familiares;

5. Participar en los Métodos de Solución de Controversias;

6. Contar con asesor jurídico;

7. Ser tratada con respeto y dignidad;

8. Recibir información del proceso;

9. Acceder a la justicia de manera pronta y expedita;

10. Ser asistido por un intérprete;

11. Repararle el daño; $y$

12. Recibir datos o elementos de prueba, etc.

${ }^{19}$ Wolbert Burgess, Regehr, Roberts, 2013, p.69.

Revista de Direito da Cidade, vol. 07, no 4. Número Especial. ISSN 2317-7721 pp.1682-1689 1686 
Como vemos, hay un protagonismo en el nuevo sistema de justicia penal mexicano de la víctima, lo que viene a configurar un control para los actores de la persecución del delito, así como de quienes deberá resolver el conflicto penal. En definitiva, la víctima que, en igualdad de condiciones, podrá tener conocimiento claro y preciso de cuál es el estatus del proceso penal que ésta ha iniciado, quedando a su criterio la posibilidad de aportar elementos para que se acceda a la verdad de los hechos sometidos en el proceso o bien, suspender, terminar o acortar, según sea el caso, el propio drama penal. Con ello tiene plena vigencia la idea relativa a que en "un estado civilizado no debería haber amigos ni enemigos, sólo inocentes y culpables"20.

\section{A MODO DE CONCLUSIÓN}

Con la reforma constitucional federal en materia de seguridad ${ }^{21}$ y justicia del año 2008, se introdujo un nuevo paradigma de justicia para República mexicana. En la exposición de motivos se establece que una de sus grandes apuestas es la introducción de la justicia restaurativa, la que tendrá una serie de obstáculos que salvar.

No será fácil llevar a cabo esta encomienda constitucional, toda vez que al constituirse el Estado Mexicano con 31 Entidades Federativas y un Distrito Federal, y teniendo presente el principio federal, se corre el riesgo que en las distintas normativas estatales no se introduzcan en su totalidad institutos, principios y reglas que garanticen un pleno acceso a la justicia del ciudadano, lo que vendría a desvirtuar parte del espíritu de la reforma. Por ello, consideramos que cuatro son los factores a tener presentes para llevar a cabo la implementación del nuevo paradigma de justicia mexicana (justicia restaurativa):

\section{El Factor jurídico}

La introducción de la justicia restaurativa conlleva la reforma y expedición de múltiples normativas en el orden, estatal y municipal, para adecuar el marco jurídico nacional con la propia reforma constitucional federal.

\footnotetext{
${ }^{20}$ Mantovani, 2003, p. 204.

${ }^{21}$ Martínez Garnelo, 2005, p. 67.
} 


\section{El Factor presupuestal}

Debe destacarse que para alcanzar los objetivos de la reforma es importante el presupuesto económico que se debe destinar para la llevar a cabo implementación de la misma (creación y/o adecuación de salas con los elementos materiales ${ }^{22}$ y tecnológicos indispensables (Calamandrei, 2004: 146), pues ésta implica la erogación pecuniaria por parte de la Federación para con los Estados.

\section{El Factor funcionarial}

La introducción del nuevo modelo de justicia implica un compromiso conjunto, de tal suerte que la sociedad y autoridades estatales deben interactuar. En este sentido, corresponderá a los operadores jurídicos impregnarse lo antes posible del espíritu de la misma, siendo asimismo indispensable asistir a cursos de capacitación para la realización exitosa de sus nuevas funciones ${ }^{23}$.

\section{El Factor cultural}

La esencia de la justicia restaurativa no sólo trastoca instituciones antes establecidas, definitivamente, la misma implica un nuevo paradigma jurídico que ha comenzado su andadura a partir del año 2008, y que incide en un cambio social, incluso, en nuestra opinión, generacional tratándose del caso mexicano (renunciar a una cultura adversarial, para optar por otra impregnada del diálogo, la concertación, etc.), que va desde el interior de la familia, pasando por los centros de enseñanza, particularmente, aquellos abocados al Derecho, que deberán reformar su curricula, e iniciar por capacitar al profesorado que impartirá la enseñanza del nuevo modelo educativo.

\section{REFERENCIAS}

CALAMANDREI, Piero. Elogio de los jueces. Escrito por un abogado. México: Oxford, 2004.

CÁMARA DE DIPUTADOS. LX Legislatura Reforma constitucional de Seguridad y Justicia. México: Cámara de diputados, 2008.

CHRISTIE, Nils. Los límites del dolor. México: Fondo de Cultura Económica, 1981.

GARCÍA RAMÍREZ, Sergio, La reforma constitucional. México: Porrúa, 2009.

${ }^{22}$ Sanz Delgado, 2003, p. 349.

23 García Ramírez, 2009, p. 233.

Revista de Direito da Cidade, vol. 07, no 4. Número Especial. ISSN 2317-7721 pp.1682-1689 1688 
La justicia vendada es incongruente, En Revista Michoacana de Derecho Penal. México, núm. 11, 1970.

GARCÍA VALDÉS, Carlos. "Una nota acerca del origen de la prisión", Historia de la prisión. Teorías economicistas. Crítica. Madrid: Edisofer, 1997.

HABERMAS, Jurgen. Facticidad y validez. Madrid: Trotta, 2001.

HIGHTON. Resolución alternativa de disputas y sistema penal. Buenos Aires: Ad-Hoc. 1998.

KEMELMAJER DE CARLUCCI, Aída. Justicia restaurativa. Argentina: Rubinzal-Culzoni Editores, 2004.

MANTOVANI, Ferrando. Conversaciones: Ferrando Mantovani. En Revista Electrónica de Ciencia Penal y Criminología, México, núm. 05, 2003.

MARTínEZ GARNELO, Jesús. Sistema nacional de seguridad pública. México: Porrúa, 2005.

MUÑOZ CONDE, Francisco. Derecho penal. Parte general. Valencia: Tirant lo Blach, 1996.

NEUMAN, Elías. La mediación penal y la justicia restaurativa. México: Porrúa, 2005.

PÁSARA, Luís. En busca de una justicia distinta. México: Instituto de Investigaciones Jurídicas, 2004.

PASTRANA AGUIRRE, Laura Aída. La justicia restaurativa como modelo de política criminal y defensa de los derechos humanos. En Prospectiva Jurídica. núm. 1, 2010.

RAWLS, John. Teoría de la Justicia. Madrid: Fondo de Cultura Económica, 1979.

RÍOS MARTíN, Julián Carlos. Mediación penal y penitenciaria. España: Colex, 2008.

ROSAS YATACO, Jorge. El sistema acusatorio en el nuevo Código procesal penal. Lima: 2005.

SANZ DELGADO, Enrique. Las viejas cárceles: Evolución de las garantías regimentales. En Anuario de Derecho Penal y Ciencias Penales, España, t. LVI, 2003.

VILLARREAL SOTELO, Karla. Principios de victimología. México: Oxford, 2011.

WOLBERT BURGESS, Ann; REGEHR, Cheryl y ROBERTS, Albert. Victimology. United States: Jones \& Bartlett learning, 2013.

Trabalho enviado em 25 de julho de 2015.

Aceito em 29 de outubro de 2015. 